\title{
論文
}

Powered Explicit Guidance 알고리듬의 위성발사체 유도 성능 분석

송은정*, 노웅래*, 조상범*, 박창수*

\section{Performance Analysis of Powered Explicit Guidance for Satellite Launch Vehicle}

Eun-Jung Song*, Woong-Rae Roh*, Sang-bum Cho* and Chang-Su Park*

\begin{abstract}
This study considers powered explicit guidance, one of the closed-loop guidance laws for satellite launch vehicles. The guidance algorithm employed here does not include the iterative procedure of the original algorithm. Also, the single-target algorithm to treat the general time-varying thrust profiles is described. The computer simulations for the $6-\mathrm{DOF}$ launch vehicle model are performed to investigate the orbit injection accuracy of the guidance algorithm in the nominal/off-nominal flight conditions.
\end{abstract}

\section{초 록}

본 논문에서는 위성발사체의 폐루프 유도방식중 하나인 Powered Explicit Guidance에 대 해서 연구하였다. 반복계산 과정이 없도록 변형시킨 알고리듬을 사용했으며, 추력변화가 큰 엔진 모델에 적용가능 하도록 단일 목표궤도에 대한 알고리듬에 대해서 기술하였다. 정상 및 비정상 비행조건에 대해서 6-자유도 컴퓨터 모의시험을 통해 얻어진 유도 알고리듬의 궤도 투입 정밀도 분석을 하였다.

Key Words : Satellite launch vehicle(위성발사체), Guidance algorithm(유도알고리듬), Explicit guidance(직접식 유도), Closed-loop guidance(폐루프 유도), 6-DOF simulation (6-자유도 모의시험)

\section{I. 서 론}

유도 알고리듬은 관성항법장치에서 측정된 가 속도벡터와 중력 가속도모델을 사용해서 현재 위 치와 속도를 계산하는 항법시스템으로부터 주어 지는 정보를 이용해서 위성을 목표궤도에 투입하 기 위해 필요한 추력벡터 방향을 결정하는 역할 을 한다. 그리고 제어 프로그램은 엔진의 응답특 성, 공기력, 발사체의 구조하중조건 등을 고려하 면서, 항법정보와 유도 프로그램의 출력값을 사

†2008년 4월 21일 접수 2008년 7월 21일 심사완료

* 정회원, 한국항공우주연구원 임무설계팀

교신저자, E-mail : ejsong@kari.re.kr

대전 유성구 어은동 45번지
용해서 엔진 김발 방향을 결정한다. 임무 달성을 위한 유도 알고리듬 설계에는 개루프와 폐루프 알고리듬 모두 사용된다. 1 단 초기에는 최대 동 압 영역을 설계된 구조하중내에 통과하기 위한 개루프 자세명령을 발사 전에 계산해서 사용한 다. 그리고 그 이후부터 궤도진입을 위해서 연료 소비를 줄일 수 있는 실시간으로 추력명령을 계 산하는 폐루프 알고리듬이 사용된다.

폐루프 유도알고리듬 중 파라미터를 이용한 유도방식(parametric guidance)에 속한 직접식 유도방식은 다른 유도방법에 비해서 많은 장점이 있으며, 현재 Ariane과 Space Shuttle 및 대부분 의 발사체는 이 방식을 사용하고 있다 [1-5].

본 논문에서는 현재까지 많이 연구된 직접식 유도방식이면서 Shuttle에 사용되는 Powered 
Explicit Guidance (PEG) [4] 를 위성발사체의 유 도를 위해 적용해 보았다. Shuttle은 임무요구사항 이 다양하기 때문에 유도, 항법, 제어 시스템

(Guidance, Navigation, and Control : GN\&C)의 요구사항도 다양하다. 반면에 Shuttle에 사용되는 탑재컴퓨터의 계산능력은 제한되어 있기 때문에 효율적인 $\mathrm{GN \& C}$ 시스템이 요구된다. 요구사항이 다양하고 효율성이 필요하기 때문에 발사체의 다 양한 상태와 연소종료시 제한 조건 등을 풀 수 있 는 유도 알고리듬이 필요하다. PEG는 이런 요구 사항들을 만족시키며, 이 문헌에서는 다양한 비행 모드를 어떻게 다루었는지에 대해서 나와 있다.

본 논문에서는 $\mathrm{PEG}$ 를 반복계산 과정이 없도 록 변형시키고 여기에 추력 프로파일의 변화가 큰 위성발사체 모델에 적용 가능한 알고리듬이 되도록 변형하였다. 이렇게 얻어진 유도알고리듬 을 $\mathrm{GN} \& \mathrm{C}$ 간의 상호 영향을 고려한 6-자유도 모 의시험을 통해 정상 및 비정상 비행조건에 대해 서 성능 분석을 수행하였다.

\section{ㅍ. 유도 알고리듬}

\subsection{PEG 알고리듬}

$\mathrm{PEG}$ 은 선형 탄젠트 유도법칙의 단순화된 벡 터형태로 표현되며 다양한 종말조건을 다룰 수 있도록 설계되었다. 흔히 요구되는 종말조건으로 는 고도, 속도, 비행방향각과 궤도면(경사각과 승 교점 경도)이 있다 [4]. 이 알고리듬의 목적은 앞 에서 말한 종말조건을 만족시키면서 추진제의 소 비를 줄일 수 있는 조종명령을 계산하는데 있다. 이러한 요구조건을 만족시키기 위해서 사용되는 선형 탄젠트 방법은 추진제를 최소화 시키는 최 적궤적에 기초를 두로 있다. 이 문제의 해는 비 행시간에 따라 추력방향이 선형으로 변화하는 형 태로 추력벡터는 다음과 같은 식으로 주어진다.

$$
\vec{u}_{F}=\frac{\vec{\lambda}_{v}+\vec{\lambda}\left(t-t_{\lambda}\right)}{\sqrt{1+\dot{\lambda}^{2}\left(t-t_{\lambda}\right)^{2}}}, \quad \dot{\lambda^{2}}=\overrightarrow{\vec{\lambda}} \cdot \overrightarrow{\vec{\lambda}}
$$

여기서

$\vec{\lambda}_{V}$ : 속도증분 방향으로의 단위벡터

$\overrightarrow{\vec{\lambda}}: \vec{\lambda}_{V}$ 에 수직인 벡터로 $\vec{\lambda}$ 의 변화율을 나타내는 벡터

$t_{\lambda}$ : 전체 속도변화가 $\vec{\lambda}_{V}$ 방향으로 되도록 선택한 시간

유도알고리듬은 predictor-corrector 방식의 반
복계산 형태로 되어있고, 파라미터 $\vec{\lambda}_{V}$ 는 최종속 도조건을 만족시킬 수 있도록 계산되며, 파라미 터 $\vec{\lambda}$ 은 위치변화를 제어할 수 있도록 결정된다.

\section{2 단순화된 $\mathrm{PEG}$ 알고리듬}

아래 유도알고리듬은 2단형 위성 발사체의 1 단 액체엔진 구간에 대해서 유도되었다. 2 단의 경우 마찬가지 방법으로 적용가능하다. 현재 발 사체의 위치, 속도가 주어질 때 추력방향을 결정 하는 파라미터 $\vec{\lambda}_{V}, \dot{\vec{\lambda}}, t_{\lambda}$ 는 다음과 같은 순서 로 결정된다.

- 알고리듬 초기화

(1) $t_{g o}$ 추정 : $t_{g o}=t_{1 \text { st stage burnout }}-t_{\text {guidance start time }}$ 유도시작시점은 궤도진입성능에 영향을 주는 요소로서 참고문헌 [6]에서는 유도시작시점에 따 라 소모되는 추진제량과 받음각 크기 사이에 trade-off 관계가 있음을 간단히 보였다. 보통 최 대동압구간이 지난 후에 폐루프 유도를 시작한 다.

(2) 1 단 엔진연소종료시점에서의 목표궤도 설정

$$
\text { - } r_{1}^{\text {target }}, v_{1}^{\text {target }}, \gamma_{1}^{\text {target }}, i_{1}^{\text {target }}, \Omega_{1}^{\text {target }}
$$

(3) (2)에서 얻어진 $i_{1}^{\mathrm{target}}, \Omega_{1}^{\mathrm{target}}$ 를 사용하여 $\mathrm{ECI}$ (Earth Centered Inertial) 좌표계에서 목표궤도면 좌표계(4-좌표계)로의 변환 $C_{I}^{4}$ 결정 (그림 1 참 조 [7])

- 매 step 마다 계산과정

(1) $\mathrm{ECI}$ 에서 위성투입궤도면과 투입점으로 정의 되는 유도좌표계(그림 1)로의 변환 결정

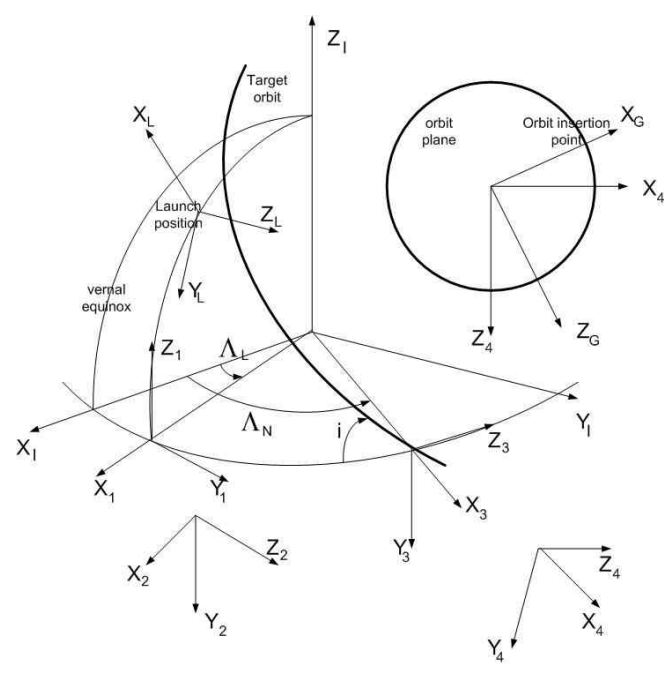

그림 1. 좌표계 정의 


$$
\begin{aligned}
C_{I}^{G} & =C_{4}^{G} C_{I}^{4} \text { 에서 } \\
C_{4}^{G} & =Y(-\xi), \quad \xi=\xi_{o}+\xi_{g o} \\
\xi_{o} & =\operatorname{atan} 2\left(Z_{4}, Y_{4}\right), \quad \overrightarrow{r^{4}}=C_{I}^{4} r \\
\xi_{g o} & \approx \frac{1}{2}\left(\frac{v \cos \gamma}{r}+\frac{v_{1}^{\mathrm{target}} \cos \gamma_{1}^{\mathrm{tar} g e t}}{r_{1}^{\mathrm{tar} g e t}}\right) t_{\mathrm{g} 0}
\end{aligned}
$$

$\xi_{g o}$ 는 근사식으로써 목표점이 멀 경우 오차가 증 가하고, 심지어 알고리듬이 수렴안할 수도 있다. 여기서는 근사값을 실제 $\xi_{g o}$ 와 비교해봄으로써 현재 사용하는 모델에서 위 근사식이 적합한지를 검토해 보았다.

(2) 유도좌표계에서의 평균 중력값 계산

$\left.\vec{v}_{\text {grav }}^{G} \approx \frac{1}{2} \overrightarrow{C_{I}^{G g}} \vec{r}\right)+C_{I}^{G \vec{g}}\left(C_{G}^{I} \overrightarrow{r_{d}^{G}}\right) t_{g o}, \vec{r}_{d}^{G}=\left(r_{1}^{\mathrm{tar} g e t}, 0,0\right)$

$\vec{r}_{g r a v}^{G} \approx \frac{2}{3} \overrightarrow{C_{I}^{G g}}(\vec{r})+\frac{1}{3} C_{I}^{G_{g}}\left(C_{G}^{I} \vec{r}_{d}^{G}\right) \frac{1}{2} t_{g o}^{2}$

위 두 식은 근사식으로서 중력가속도에 의해서 $t_{g o}$ 동안 얻을 수 있는 속도와 위치변화를 나타낸 다. 참고문헌 [4]에서는 비행시간이 길 경우 위 식은 오차가 커지는 문제가 있어 적분을 통해 $\vec{v}_{g r a v}^{G}, \vec{r}_{g r a v}^{G}$ 를 정확도를 개선하는 방법을 제안하 고 있다. 여기에서는 간단히 위 근사식을 사용해 서 얻어진 결과를 실제 $\vec{v}_{g r a v}^{G}, \vec{r}_{g r a v}^{G}$ 와 비교해봄으 로써 현재 주어진 모델에 위 식이 적합한지를 검 토해보았다.

(3) $\vec{V}_{g o}^{G}$ 와 $\vec{\lambda}_{V}^{G}$ 계산 : prediction \& correction 과정을 생략하기위해서 $\vec{V}_{g o}^{G}$ 를 다음과 같이 계산

$$
\begin{aligned}
\vec{V}_{g o}^{G} & =\vec{V}_{d}^{G}-\vec{V}^{G}-\vec{V}_{g r a V}^{G} \\
\vec{\lambda}_{V}^{G} & =\frac{\vec{V}_{g o}^{G}}{\left|\vec{V}_{g o}^{G}\right|}
\end{aligned}
$$

(4) $t_{g_{0}}$ 와 추력적분값 $L, J, S, Q$ 를 계산 (주로 $t_{g o}$ 나 관성항법장치에서 측정된 가속도 이용)

현재 1 단 추력 프로파일에 적합한 $t_{g o}$ 및 추력 적분값 $L, J, S, Q$ 는 다음절에 구체적으로 나와 있다. 여기서 사용하고 있는 알고리듬은 $\dot{\lambda}^{2}$ 을 무 시함으로써 결과적으로 고차의 추력적분값 $H, P$ 를 무시한 알고리듬이다 [4].

$L=\int_{0}^{t_{g o}}(F / m) d t, \quad S=\int_{0}^{t_{g o}} \int_{0}^{t}(F / m) d s d t$ $J=\int_{0}^{t_{g o}}(F / m) t d t, \quad Q=\int_{0}^{t_{g o}} \int_{0}^{t}(F / m) s d s d t$

(5) $\dot{\vec{\lambda}}$ 계산 $\left(\dot{\vec{\lambda}}\right.$ 과 $\overrightarrow{\lambda_{V}}$ 가 서로 수직이라는 조건 사 용)

$$
\begin{aligned}
& \vec{r}_{g o}^{G}=\vec{r}_{d}^{G}-\vec{r}^{G}-\vec{V}^{G} t_{g o}-\vec{r}_{g r a V}^{G} \\
& t_{\lambda}=\frac{J}{L} \\
& \tilde{\lambda}_{x}{ }^{G}=\frac{r_{g o_{X}}{ }^{G}-S \lambda_{V_{X}}{ }^{G}}{Q-S t_{\lambda}}, \\
& \bar{\lambda}_{y}{ }^{G}=\frac{r_{g o_{y}}{ }^{G}-S \lambda_{V_{y}}{ }^{G}}{Q-S t_{\lambda}}, \\
& \tilde{\lambda}_{z}{ }^{G}=-\frac{\bar{\lambda}_{x}{ }^{G} \lambda_{V_{X}}^{G}+\tilde{\lambda}_{y}{ }^{G} \lambda_{V_{Y}}^{G}}{\lambda_{V_{Z}}^{G}}
\end{aligned}
$$

(6) 조종 파라미터 $\vec{\lambda}_{n} \overrightarrow{\vec{\lambda}}, t_{\lambda}$ 를 유도/제어 조종 인터페이스부에 전달한다. 새로운 조종파라미터 가 주어질 때까지 추력벡터 방향은 유지된다. 이 로부터 발사체 좌표계에 대한 피치명령과 요명령 이 계산된다.

(7) 다음 단계에서의 계산을 위해서

$$
t_{g o}{ }^{\prime}=t_{g o}-h
$$

여기서 $h$ 는 조종파라미터가 update 되는 간격이 다. $h$ 가 크면 클수록 정밀도가 떨어진다.

- 유도알고리듬 계산과정의 종료

유도명령의 발산을 막기 위해서 추력정지 몇 초 이전부터 $\overrightarrow{\lambda_{n}} \dot{\vec{\lambda}}$ 와 $t_{\lambda}$ 는 고정된 값을 사용한 다. 또는 $\hat{\Theta}_{c}, \bar{\Psi}_{c}$ 를 일정한 값으로 유지한다 (rate hold 명령).

- 추력종료시점 결정

단계 (4)에서 계산된 $t_{g o}$ 가 0 이 되는 순간 추력을 종료하게 된다. 유도 명령은 $\left|\overrightarrow{v_{g o}}\right|$ 가 정해진 값 이 내로 줄어들면 더 이상 계산되지 않지만 그 이후 에도 추력종료시점 결정을 위한 $t_{g o}$ 계산은 계속되 고, 이 값에 따라 추진제 사용량도 변하게 된다.

\section{3 추력적분값 및 $t_{g o}$ 계산}

추력적분값은 유도성능에 영향을 주는 요인으 로서 정확한 계산이 필요하다. 추력 프로파일이 주어지게 되면 추력 특성을 잘 모사한 추력모델 을 사용하여 추력적분값을 계산하는데, 보통 일 정추력모델이나 일정가속도모델을 사용하여 계산 한다. 추력 프로파일을 단순히 하나의 모델로 나 타낼 수 없는 경우에는 여러 구간으로 나누어 각 구간마다 적합한 모델을 사용하여 추력적분값을 계산한 후, 전체 추력적분값은 다단발사체에서 단일 표적 문제와 같이 여러 단의 추력적분값을 더하는 방법을 사용하여 계산한다. 그림 2 와 같 이 추력 프로파일을 나눌 경우 $\mathrm{j}$ 번째 단계에서 추력적분값은 다음과 같이 주어진다. 


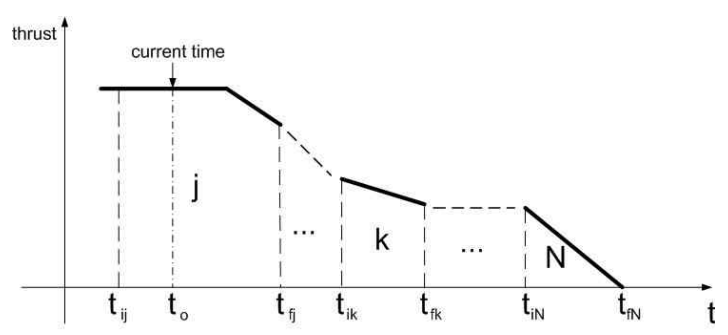

그림 2. 일반적인 추력 선도

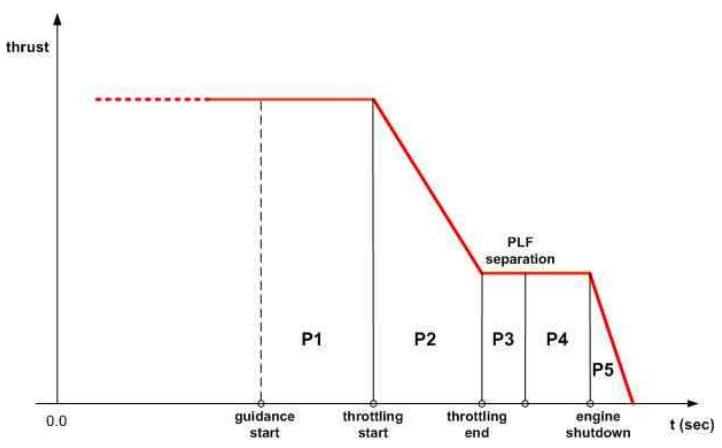

그림 3. 1단 추력선도

$$
\begin{aligned}
L= & \sum_{k=j}^{N} L_{k}, \quad j=1,2, \cdots, N-1 \\
J= & \sum_{k=j}^{N} J_{k}+\sum_{k=j+1}^{N}\left(t_{i k}-t_{o}\right) L_{k} \\
S= & \sum_{k=j}^{N} S_{k}+\sum_{k=j}^{N-1}\left(t_{f N}-t_{f k}\right) L_{k} \\
& \quad(j=N-1 \text { 이면 } 2 \text { 번째 항 }=0) \\
Q= & \sum_{k=j}^{N} Q_{k}+\left(t_{f N}-t_{f j}\right) J_{j}+\sum_{k=j+1}^{N}\left(t_{i k}-t_{o}\right) S_{k} \\
& +\sum_{k=j+1}^{N-1} m\left(t_{f N}-t_{f k}\right) J_{k}+\left(t_{f N}-t_{f k}\right)\left(t_{i k}-t_{o}\right) L_{k f} \\
& (j=N-1 \text { 이면 } 3,4 \text { 번째 항 }=0)
\end{aligned}
$$

여기서 $L_{j}, J_{j}, S_{j}, Q_{j}$ 는 $\mathrm{j}$ 번째 단계에서 $\mathrm{j}$ 번째 단 계 종료 시점까지의 $t_{g o}$ 에 따른 추력적분값을, $L_{j+1}, J_{j+1}, S_{j+1}, Q_{j+1}, \cdots, L_{N}, J_{N}, S_{N}, Q_{N}$ 은 각 단계에서의 시작시점에서의 그 단계종료시점까지 의 추력적분값을 나타낸다. 여기서 사용한 위성 발사체의 1 단 추력프로파일의 경우 그림 3 과 같 이 추력변화가 큰 경우로 다음과 같이 5 개의 구 간 $(\mathrm{P} 1, \mathrm{P} 2, \mathrm{P} 3, \mathrm{P} 4, \mathrm{P} 5)$ 으로 나누어서 추력적분값 을 계산하였다.

-구간 $1, \mathrm{P} 1$ : 일정추력

폐루프 유도시작시점부터 가속도가 비행 전에 정한 최대 값 (구조하중 제한조건으로부터 유도
됨)에 도달하는 시점까지의 구간으로 이 이후부 터는 추력조절(throttling)이 되는 구간이 시작된 다.

-구간 2, P2: 일정가속도 또는 수치적으로 추력 적분값 계산

이 구간은 시작시점과 관계없이 유지시간이 고정되어있다. 선형 추력 프로파일이어서 참고문 헌 [5]에 나온 방법으로 추력적분값 계산을 고려 해보았으나 이 문헌에서는 Isp를 일정한 값으로 두고, 해석적인 추력적분값을 유도하였고 Isp가 선형적으로 변하는 문제로 쉽게 확장할 수 없었 다. 여기서는 수치적으로 추력적분값을 계산하여 사용하였다.

-구간 3, P3: 일정 추력

PLF 분리이전까지 구간이다 (PLF 분리에 따른 질량변화로 추력적분값이 영향을 받게 되므로 구 간 3 과 구간 4 를 나누었다. 참고문헌 [8]에서는 이 문제에 대해서 다루었다).

-구간 4, P4: 일정 추력

구간종료시점은 1 단 연소시점에서의 요구속도 조건을 만족시킬 수 있도록 이 구간의 지속시간 을 결정하였다.

-구간 5, P5: 수치적으로 추력적분값 계산

이 구간은 매우 짧은 구간으로 고정되어있다.

구간별 $t_{g o}$ 변화, 시작 및 종료 시점은 다음과 같이 계산된다. 여기서 $t_{i(\cdot)}$ 와 $t_{f(\cdot)}$ 는 각 구간의 시작시점 및 종료시점을 나타낸다.

- 구간 $1: t_{o} \in\left[\begin{array}{ll}t_{i_{1}} & t_{f_{1}}\end{array}\right]$

- 구간 1 에서의 추력적분값 및 $t_{g o}$

가속도가 $a_{m}$ 까지 도달하는데 걸리는 시간으로 부터 $t_{g o}$ 는 다음과 같이 계산된다.

$t_{g o_{1}}=\tau\left(1-\frac{a_{o}}{a_{m}}\right), \quad a_{o} \leqq a_{m}$

$L_{1}=V_{e x_{1}} \ln \frac{\tau}{\left(\tau-t_{g o_{1}}\right)}, \quad \tau=\frac{V_{e x_{1}}}{a_{o}}$

$J_{1}=V_{e x_{1}}\left[\ln \frac{\tau}{\left(\tau-t_{g o_{1}}\right)}-t_{g o_{1}}\right]$

$S_{1}=-V_{e x_{1}}\left[\left(\tau-t_{g o_{1}}\right) \ln \frac{\tau}{\left(\tau-t_{g o_{1}}\right)}-t_{g o_{1}}\right]$

$Q_{1}=-V_{e x_{1}}\left[\frac{t_{g o_{1}}{ }^{2}}{2}+\tau\left(\tau-\mathrm{t}_{\mathrm{go}_{1}}\right) \ln \frac{\tau}{\left(\tau-t_{g o_{1}}\right)}-t_{g o_{1}}\right]$

- 구간 2 에서의 추력적분값 및 $t_{g o}$ $L_{2}, J_{2}, S_{2}, Q_{2}$ 는 사전에 계산된 값을 $t_{g o_{2}}$ 는 사전 에 정해진 값을 사용한다. 
- 구간 3 에서의 추력적분값 및 $t_{g o}$

$L_{3}, J_{3}, S_{3}, Q_{3}$ 는 사전에 계산된 값을 $t_{g 0_{3}}$ 는 사 전에 정해진 값을 사용한다.

- 구간 4 에서의 추력적분값 및 $t_{q o}$

$$
\begin{aligned}
& L=L_{1}+L_{2}+L_{3}+L_{4}+L_{5}=\left|\overrightarrow{v_{g o}}\right| \\
& L_{4}=\left|\overrightarrow{v_{g o}}\right|-\left(L_{1}+L_{2}+L_{3}+L_{5}\right) \\
& =V_{e x_{4}} \ln \frac{\tau\left(t_{i_{4}}\right)}{\tau\left(t_{i_{4}}\right)-t_{g o_{4}}}, \quad \tau\left(t_{i_{4}}\right)=\frac{V_{e x_{4}}}{a\left(t_{i_{4}}\right)} \\
& t_{g o_{4}}=\tau\left(t_{i_{4}}\right)\left[1-\exp \left\{-\frac{\left|\overrightarrow{v_{g o}}\right|-\left(L_{1}+L_{2}+L_{3}+L_{5}\right)}{V_{e x_{4}}}\right\}\right] \\
& J_{4}=V_{e x_{4}}\left[\tau\left(t_{i_{4}}\right) \ln \frac{\tau\left(t_{i_{4}}\right)}{\tau\left(t_{i_{4}}\right)-t_{g o_{4}}}-t_{g o_{4}}\right] \\
& S_{4}=-V_{e x_{4}}\left[\left(\tau\left(t_{i_{4}}\right)-t_{g o_{4}}\right) \ln \frac{\tau\left(t_{i_{4}}\right)}{\tau\left(t_{i_{4}}\right)-t_{g o_{4}}}-t_{g o_{4}}\right] \\
& Q_{4}=-V_{e x_{4}}\left[\frac{t_{g o_{4}}{ }^{2}}{2} \cdots\right. \\
& \left.+\tau\left(t_{i_{4}}\right)\left\{\left(\tau\left(\mathrm{t}_{\mathrm{i}_{4}}\right)-\mathrm{t}_{\mathrm{gO}_{4}}\right) \ln \frac{\tau\left(t_{i_{4}}\right)}{\tau\left(t_{i_{4}}\right)-t_{g o_{4}}}-t_{g o_{4}}\right\}\right]
\end{aligned}
$$

- 구간 5 에서의 추력적분값 및 $t_{g o}$

$L_{5}, J_{5}, S_{5}, Q_{5}$ 는 사전에 계산된 값 $t_{g 0_{5}}$ 는 사 전에 정해진 값을 사용한다.

위에서 계산된 각 구간의 추력적분값을 사용 하여 전체 $L, J, S, Q$ 는 식 (1) 통해 계산하고 구간별 시작 및 종료시점은 다음과 같이 유도된 다. 여기서 $\hat{t}_{(\cdot)}$ 은 PEG에 의해서 새로이 계산되 어 update된 시간을 나타내고, $t_{(\cdot o)}$ 는 발사 전에 nominal한 상황에서 계산된 시간을 나타낸다.

$$
\begin{aligned}
& \hat{t}_{f_{1}}=t_{o}+t_{g o_{1}} \\
& \hat{t}_{f_{2}}=\hat{t}_{f_{1}}+\left(t_{f_{2 o}}-t_{f_{1 o}}\right) \\
& \hat{t}_{f_{3}}=\hat{t}_{f_{2}}+\left(t_{f_{3 o}}-t_{f_{2 o}}\right) \\
& \hat{t}_{f_{4}}=\hat{t}_{f_{3}}+t_{g o_{4}} \\
& \hat{t}_{f_{5}}=\hat{t}_{f_{4}}+\left(t_{f_{5 o}}-t_{f_{4 o}}\right)
\end{aligned}
$$$$
\text { 이로부터 전체 } t_{g o} \text { 는 }
$$

$t_{\text {go }}=\hat{t}_{f_{5}}-t_{o}$

- 구간 2: $t_{o} \in\left[\begin{array}{ll}t_{i_{2}} & t_{f_{2}}\end{array}\right]$

- 구간 2 에서의 추력적분값 및 $t_{g o}$

수치적으로 계산된 추력적분값을 사용할 경우 는 $t_{g o}$ 에 따른 추력적분값 표를 선형내삽을 통해 계산하면 되고 일정 가속도 모델로 근사하는 경 우에는 다음과 같이 계산된다. $t_{g o_{2}}=\hat{t}_{f_{2}}-t_{o}$

$L_{2}=\bar{a} t_{g o_{2}}, \quad S_{2}=\frac{1}{2} \bar{a} t_{g o_{2}}^{2}$

$J_{2}=\frac{1}{2} \bar{a} t_{g o_{2}}^{2}, \quad Q_{2}=\frac{1}{6} \bar{a} t_{g o_{2}}^{3}$

- 구간 $3,4,5$ 에서의 추력적분값 및 $t_{g o}$

앞의 구간 1 에서 기술되어 있는 구간 $3,4,5$ 와 비슷한 방법으로 계산하면 된다.

구간 1 에서와 같이 위에서 계산된 각 구간의 추력적분값을 사용하여 전체 $L, J, S, Q$ 는 식 (1)을 통해 계산하고 구간별 시작 및 종료시점도 비슷한 방식으로 유도할 수 있다.

- 구간 3: $t_{o} \in\left[\begin{array}{ll}t_{i_{3}} & t_{f_{3}}\end{array}\right]$

- 구간 3 에서의 추력적분값 및 $t_{g o}$

$t_{g o_{3}}=\hat{t}_{f_{3}}-t_{o}$

$L_{3}=V_{e x_{3}} \ln \frac{\tau}{\left(\tau-t_{g o_{3}}\right)}$

$J_{3}=V_{e x_{3}}\left[\ln \frac{\tau}{\left(\tau-t_{g O_{3}}\right)}-t_{g o_{3}}\right]$

$S_{3}=-V_{e x_{3}}\left[\left(\tau-\mathrm{t}_{\mathrm{gO}_{3}}\right) \ln \frac{\tau}{\left(\tau-t_{g 0_{3}}\right)}-t_{g 0_{3}}\right]$

$Q_{3}=-V_{e x_{3}}\left[\frac{t_{g o_{3}}{ }^{2}}{2}+\tau\left(\tau-\mathrm{t}_{\mathrm{gO}_{3}}\right) \ln \frac{\tau}{\left(\tau-t_{g 0_{3}}\right)}-t_{g 0_{3}}\right]$

- 구간 4,5 에서의 추력적분값 및 $t_{g o}$

구간 1 에서 기술되어 있는 방법과 비슷한 방 법으로 계산한다.

- 구간 $4: \quad t_{o} \in\left[\begin{array}{ll}t_{i_{4}} & t_{f_{4}}\end{array}\right]$

- 구간 4 에서의 추력적분값 및 $t_{g o}$

$L=L_{4}+L_{5}=\left|\overrightarrow{v_{g o}}\right|$

$L_{4}=\overrightarrow{\left|\overrightarrow{v_{g}}\right|}-L_{5}=V_{e x_{4}} \ln \frac{\tau\left(t_{i_{4}}\right)}{\tau\left(t_{i_{4}}\right)-t_{g o_{4}}}, \quad \tau\left(t_{i_{4}}\right)=\frac{V_{e x_{4}}}{a\left(t_{i_{4}}\right)}$

$t_{g o_{4}}=\tau\left(t_{i_{4}}\right)\left[1-\exp \left\{-\frac{\overrightarrow{\left|\overrightarrow{v_{o}}\right|}-L_{5}}{V_{e x_{4}}}\right\}\right]$

$J_{4}, S_{4}, Q_{4}$ 는 주어진 $t_{g 0_{4}}$ 에 대해서 구간 1 과 같이 계산한다.

- 구간 5 에서의 추력적분값 및 $t_{g o}$

구간 1 에서 기술되어 있는 방법과 비슷한 방 법으로 계산한다

\section{4 유도필터 설계}

앞에서 얻어진 유도명령은 항법시스템으로부 터 새로운 정보가 주어질 때까지 일정한 값으로 유지된다. 일정시간동안 유지된 유도명령은 다음 
단계에서의 유도명령과 어느 정도 차이가 생기게 되고 이로부터 새로운 명령이 얻어질 때마다 이 를 추종하기 위한 제어입력값은 급격하게 변하게 된다. 이를 방지하기 위해선 유도알고리듬으로부 터 얻어진 유도명령을 매끈하게 만들기 위한 유 도필터가 필요하게 된다. Shuttle에서는 2차 전달 함수 형태의 필터를 사용하였고 [3], 본 논문에서 도 Shuttle에 사용된 유도필터를 현재 사용하고 있는 모델에 적합하도록 필터 파라미터만 바꾸어 사용하였다. 이 때 필요한 유도명령 변화율도 같 은 방법으로 계산했다. 유도 명령 변화율은 아래 와 같이 2차 전달함수 형태에 따라 필요 없을 수 도 있는데 사용하지 않을 경우 사용하는 경우에 비해서 위상 지연이 커지게 된다.

- 유도명령 변화율이 필요한 경우

$$
\frac{\theta_{d}}{\theta_{c}}=\frac{2 \xi \omega_{n} s+\omega_{n}^{2}}{s^{2}+2 \xi \omega_{n} s+\omega_{n}^{2}}
$$

- 유도명령 변화율이 필요 없는 경우

$$
\frac{\theta_{d}}{\theta_{c}}=\frac{\omega_{n}^{2}}{s^{2}+2 \xi \omega_{n} s+\omega_{n}^{2}}
$$

\section{III. 수치결과}

\section{1 정상비행조건}

유도 알고리듬 관련 사용된 설계 파라미터 값 들은 표 1 과 같다. 여기서 유도시작시점은 최대 동압구간을 지나 거의 공기력 영향이 없는 시점 으로 두었다.

2 단 구간에서 대해서는 1 단과 같은 방법으로 $\mathrm{PEG}$ 를 설계하여 수치결과를 얻었다. 궤도투입 성능 분석을 위한 6-DOF 모의시험은 제어, 항법 시스템과의 상호관계를 고려한 모의시험이 된다. 그림 4는 이런 유도, 항법, 제어 시스템간의 상호 관계를 나타내는 블록 선도로 제어기는 간단히 $\mathrm{PID}$ 제어기를, 항법 알고리듬은 오일러 적분방식 을 사용하였다. 따라서 항법알고리듬으로부터 제 공되는 가속도, 속도, 위치, 자세 정보는 간단한 적분 방법으로 인한 오차만 존재하게 된다 (IMU 에 의한 센서오차는 무시하였다).

\section{표 1. 유도 알고리듬 관련 파라미터}

유도 필터 : $\xi=\frac{1}{\sqrt{2}}, \omega_{n}=2.74(\mathrm{rad} / \mathrm{s})$
유도 명령 update : 매 0.5 초
유도 알고리듬 종료 : $\left|\overrightarrow{v_{g o}}\right| \leqq 400(\mathrm{~m} / \mathrm{sec})$

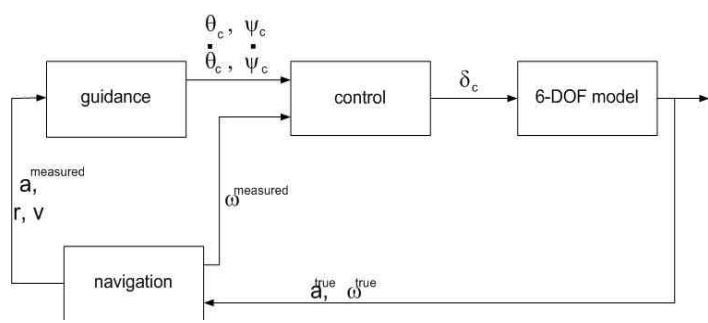

그림 4. 6-DOF 모의시험 블럭선도

모의시험은 다음과 같이 3 가지 경우에 대해서 수행하였다. 이 중 (a)와 (b)는 아래 식과 같이 자세변화율명령 피드백에 따른 궤도투입오차를 비교하기 위한 모의시험이다. 개루프 명령은 탑 재 위성의 질량을 최대화하는 최적화문제의 해로 부터 얻어졌다.

$$
\delta_{p}=K_{p}\left(\theta_{c m d}-\theta\right)+K_{I} \int\left(\theta_{c m d}-\theta\right) d t+K_{d}\left(\dot{\theta}_{c m d}-\dot{\theta}\right)
$$

(a) Open-loop 명령 + PID 제어기에 자세변화율 명령이 없음 $\left(\dot{\theta}_{c m d}=0\right)$

(b) Open-loop 명령 $+\mathrm{PID}$ 제어기에 자세변화율 명령이 있음

(c) $\mathrm{PEG}+$ filter + PID 제어기에 자세변화율명 령이 없음 $\left(\dot{\theta}_{c m d}=0\right)$

그림 5 는 근사식의 정확도 분석하기 위해 $\mathrm{PEG}$ 알고리듬을 사용해서 모의시험 수행 후 얻 어지는 데이터를 사용하여 실제값을 계산하고 여 기에 $\mathrm{PEG}$ 알고리듬에서 예측한 값을 비교한 그 림이다. 초기에는 실제값과 다소 차이가 있지만 오차가 줄어듬을 알 수 있다 (여기서는 생략했지 만 $v_{g r a v}, r_{g r a v}, v_{g o}, r_{g o}$ 도 마찬가지 결과를 보임) 그림 6 은 2.3절에서 설명한 방법을 사용하여 계 산한 추력적분값 $L$ 을 나타낸다. 매끈하게 변함을 알 수 있다 $(J, S, Q$ 도 마찬가지 결과를 보임).

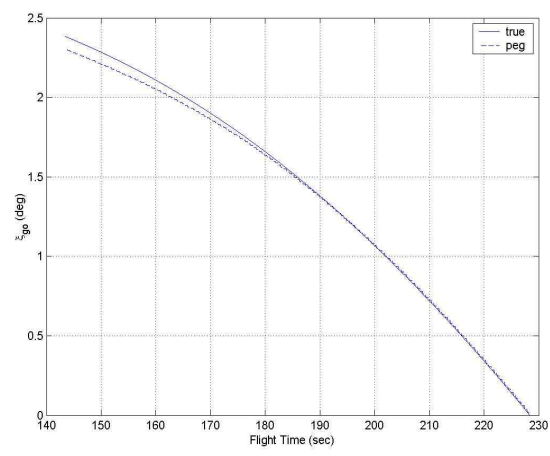

그림 5. $\xi_{q o}$ 


\section{표 2. 1단 연소종료시점에서의 궤도투입오차}

\begin{tabular}{|ccccc|}
\hline & $\begin{array}{c}\text { Velocity } \\
(\mathrm{m} / \mathrm{s})\end{array}$ & $\begin{array}{c}\text { Gamma } \\
(\mathrm{deg})\end{array}$ & $\begin{array}{c}\text { Radius } \\
(\mathrm{m})\end{array}$ & \multicolumn{1}{c|}{ INC } \\
$(\mathrm{deg})$ \\
(a) & -4.31171 & 0.16798 & 995.82661 & -0.02145 \\
$(\mathrm{~b})$ & 0.49925 & -0.00268 & 46.93943 & -0.01757 \\
$(\mathrm{c})$ & 0.14145 & -0.00770 & 31.19331 & 0.00196 \\
\hline
\end{tabular}

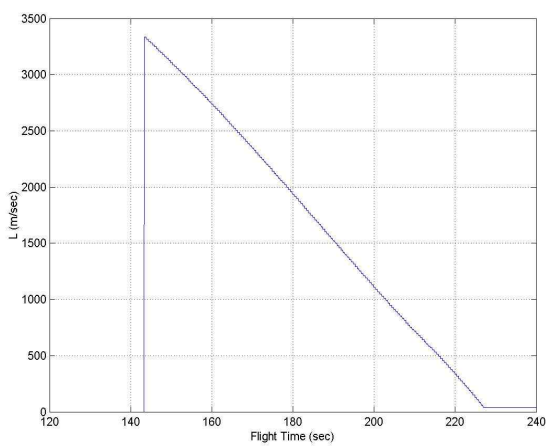

그림 6. 추력적분값 $\mathrm{L}$

표 2에 요약된 궤도투입 정밀도를 보면 $\mathrm{PEG}$ 의 경우 속도오차(Velocity) $0.15 \mathrm{~m} / \mathrm{s}$ 이내, 고도오차 (Radius) $40 \mathrm{~m}$ 이내, 궤도경사각(INC) 0.002 도 이 내로 Open-loop 명령에 비해서 더 우수함을 알 수 있다 (Open-loop의 경우 자세명령변화율을 피드백할 경우 안하는 경우에 비해서 더 우수함 을 알 수 있다).

\section{2 비정상비행조건}

1 단 구간에서의 오차요인을 크게 바람 영향과 파라미터 변화 영향으로 나누어서 분석하였다. 바람 영향의 경우 비행 전 바람을 고려하여 설계 된 명령 프로파일에 따라 성능이 다르게 되는데 본 논문에서는 바람의 영향을 고려하지 않고 설 계된 개루프 명령에 대해서 분석을 수행하였다. 일반적으로 발사체의 경우 모든 바람 프로파일에 대해서 비행이 가능하도록 설계되지 않으며, 주 엔진의 제어각에 의해서 측정되는 제어 모멘트와 동압과 받음각의 곱에 의해서 측정되는 구조 하 중 모니터링을 통해서 $\mathrm{Go} / \mathrm{No}-\mathrm{Go}$ 결정을 한다. 우주 발사체는 바람에 의한 발사중지로 인해서 상당한 비용 손실이 발생하기 때문에 예상되는 비행 중 하중을 최소화 하도록 발사 전에 궤적 설계를 하거나 축하중을 측정해서 비행 중 자동 조종장치를 사용해서 보상하는 방법을 사용한다. Delta 발사체 경우는 대기권을 통과하는 동안 하 중경감유도를 사용하여 온보드 상의 바람정보를

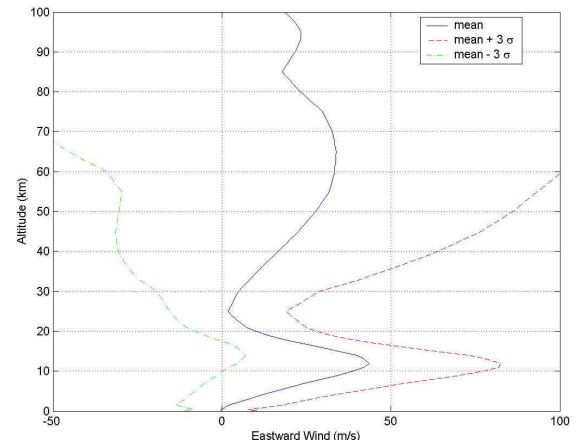

(a) 서풍

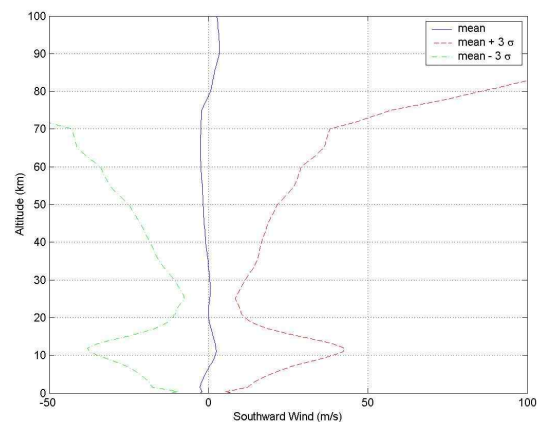

(b) 북풍

\section{그림 7. 발사장 지역의 바람 프로파일}

이용하여 받음각을 최소화하고 발사체의 하중을 감소시켰다 [9]. 본 논문에서는 $3 \sigma$ 바람에 의한 $\mathrm{Go} / \mathrm{No}^{-} \mathrm{Go}$ 문제는 다루지 않았으며 1단 연소종 료시점에서의 궤도 정밀도만을 분석하였다. 바람 모델은 아래 그림과 같이 GRAM-95 모델에 대해 서 10 월 발사장 위치에서의 수직 바람 프로파일 을 사용하였다.

바람외의 각종 파라미터의 $3 \sigma$ 분산값은 참고 문헌 [10]를 바탕으로 다음과 같이 두었다.

$$
\begin{array}{ll}
\text { - 추력 } & \pm 0.5 \% \\
\text { - 비추력 } & \pm 0.1 \% \\
\text { - 구조 중량 } & \pm 0.35 \% \\
\text { - 추진제 중량 } & \pm 0.35 \% \\
\text { - 항력 계수 } & \pm 10.0 \%
\end{array}
$$

각 오차요인의 $\pm 3 \sigma$ 오차 값에 대해서 6-DOF 모의시험을 통해 1 단 연소종료시점에서의 궤도 투입 오차 성능을 검증하였다.

표 3 은 바람 영향이 있는 경우의 1 단 구간에 서의 궤도 투입오차 모의시험결과를 나타낸다. (b)는 정상비행조건에서 (a)보다 우수한 성능을 
표 3. 바람 영향이 있는 경우의 1 단 연소종료 시점에서의 궤도 투입오차

\begin{tabular}{|c|c|c|c|c|}
\hline $\begin{array}{l}\text { wind } \\
\text { condition }\end{array}$ & $\begin{array}{r}\text { Velocity } \\
(\mathrm{m} / \mathrm{s})\end{array}$ & $\begin{array}{r}\text { Gamma } \\
\text { (deg) }\end{array}$ & $\begin{array}{r}\text { Radius } \\
(\mathrm{km})\end{array}$ & $\begin{array}{l}\text { INC } \\
\text { (deg) }\end{array}$ \\
\hline \multicolumn{5}{|c|}{ (a) } \\
\hline mean & -0.72477 & 0.15028 & 0.80464 & 0.14986 \\
\hline mean $+3 \sigma$ & -13.09710 & 0.19871 & 1.32774 & 0.35391 \\
\hline mean-3 $\sigma$ & 11.15437 & 0.09203 & 0.11457 & 0.05162 \\
\hline \multicolumn{5}{|c|}{ (b) } \\
\hline mean & $4.08463-$ & -0.02025 & -0.14489 & -0.14569 \\
\hline mean+3o & -8.29275 & 0.02789 & 0.38221 & -0.34938 \\
\hline mean-3o & 15.96113 & -0.07819 & -0.83851 & 0.05541 \\
\hline \multicolumn{5}{|c|}{$(\mathrm{c})$} \\
\hline mean & $0.26250-$ & -0.00261 & 0.03908 & 0.04100 \\
\hline mean+3o & -0.51245 & -0.03977 & 0.03020 & 0.10519 \\
\hline 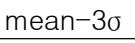 & 0.65973 & 0.00487 & 0.03064 & -0.00717 \\
\hline
\end{tabular}

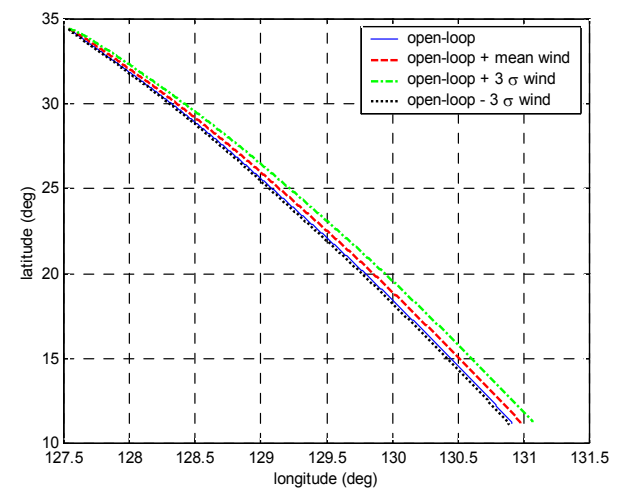

그림 8. 궤적 (open-loop + 바람 영향)

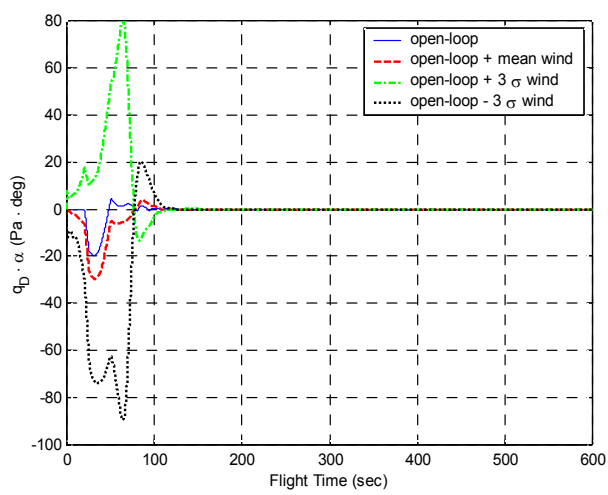

그림 9. 동압x받음각 (open-loop + 바람 영향)

보였으나, 바람 영향이 있는 경우에는 비슷한 성 능을 보인다. (a)와 (b)는 $15.96 \mathrm{~m} / \mathrm{s}$ 수준의 속도, $1.33 \mathrm{~km}$ 수준의 고도, $0.35 \mathrm{deg}$ 수준의 경사각 오 차를 보이는 반면에 $\mathrm{PEG}$ 는 각각 $0.66 \mathrm{~m} / \mathrm{s}$,

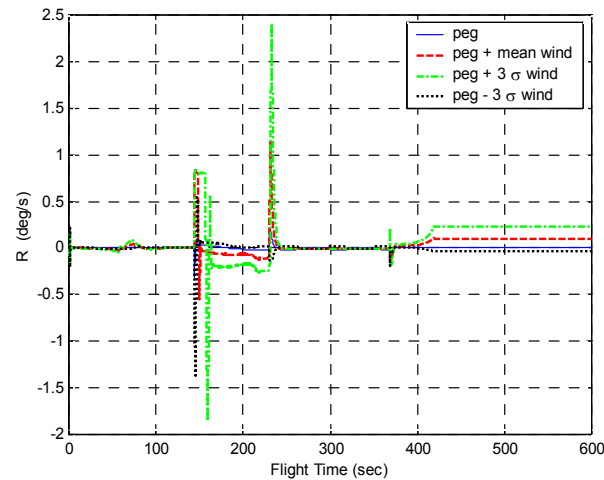

그림 10. 요각속도 (PEG + 바람 영향)

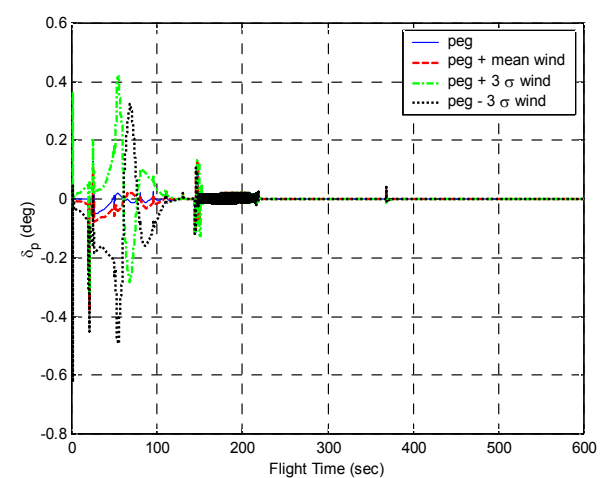

그림 11. 피치제어각 (PEG + 바람 영향)

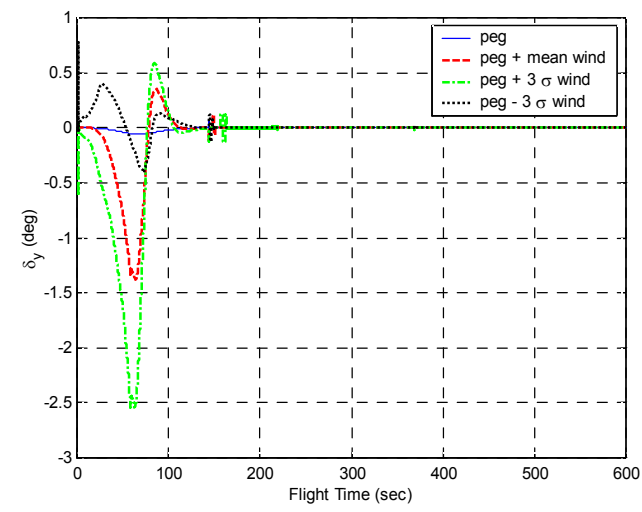

그림 12. 요제어각 (PEG + 바람 영향)

$0.04 \mathrm{~km}, 0.11 \mathrm{deg}$ 수준의 오차를 보여 바람에 의 한 궤적 오차를 잘 보상함 알 수 있다.

그림 8 부터 12 는 모의시험으로부터 얻어진 궤 적을 나타낸다. 바람에 의해서 궤적이 횡방향으 로 벗어나게 되고 동압x받음각도 nominal 값에 비해 증가하게 된다. 이로 공력 구간에서 생긴 
표 4. $+3 \sigma$ 파라미터 변화가 있는 경우의 1 단 연소종료시점에서의 궤도 투입오차

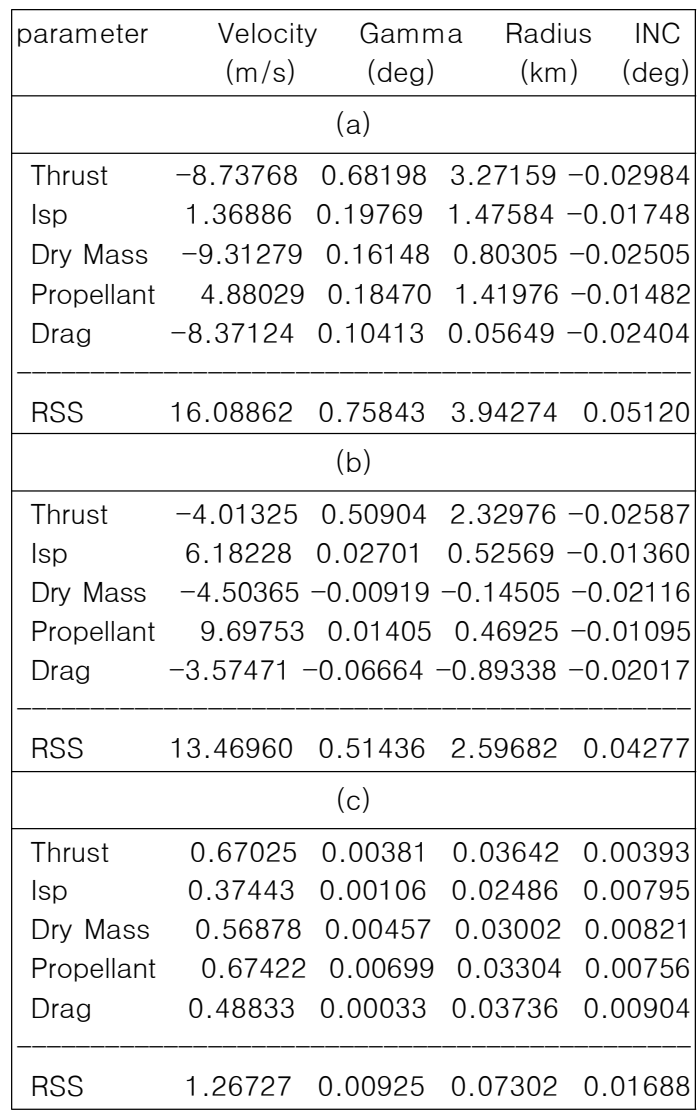

오차를 보상하기 위해서 요 제어각이 $2.5 \mathrm{deg}$ 까지 증가함을 할 수 있다 (다른 횡방향 관련 변수인 요각속도, 옆미끄럼각도 많이 증가한다). 피치제 어각도 nominal 값에 비해 $0.5 \mathrm{deg}$ 까지 증가함 을 알 수 있다.

표 4는 파라미터 오차가 있는 경우의 모의시 험 결과를 나타낸다 ( $-3 \sigma$ 의 경우도 비슷한 결과 를 보임). (a)와 (b) 중 (b)가 조금 더 우수하며 (c)가 가장 우수함을 알 수 있다. 전체 파라미터 변화에 대한 오차의 RSS 값이 (a)의 경우 속도오 차 $16.09 \mathrm{~m} / \mathrm{s}$ 이내, 고도오차 $3.95 \mathrm{~km}$ 이내, 궤도 경사각 $0.06 \mathrm{deg}$ 이내인 반면 (c)의 경우 속도오차 $1.27 \mathrm{~m} / \mathrm{s}$ 이내, 고도오차 $0.08 \mathrm{~km}$ 이내, 궤도경사 각 $0.02 \mathrm{deg}$ 이내이다. (c)의 경우 추력종료시점 조종을 통한 속도제어가 가능하기 때문에 파라미 터 변화가 있는 경우에도 궤도투입오차가 적게 된다. 유도명령 update시간은 0.5초로 두었는데 일반적으로 $t_{g o}$ 가 줄어듬에 따라 update 시간도 줄여줘서 보다 정확하게 추력종료시점을 계산하

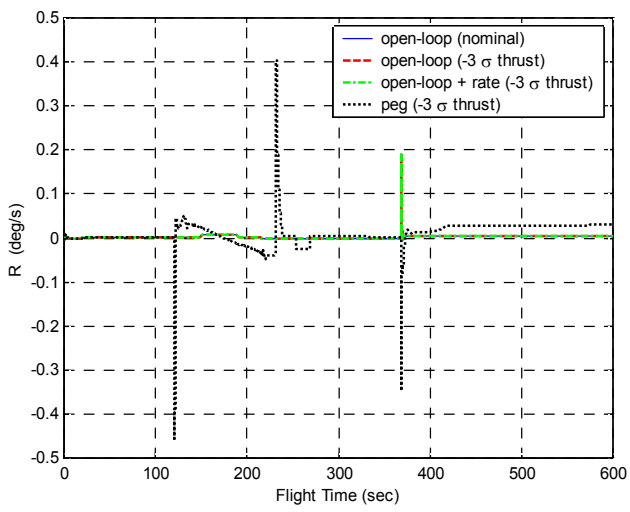

그림 13. 요각속도 $(-3 \sigma$ 추력오차)

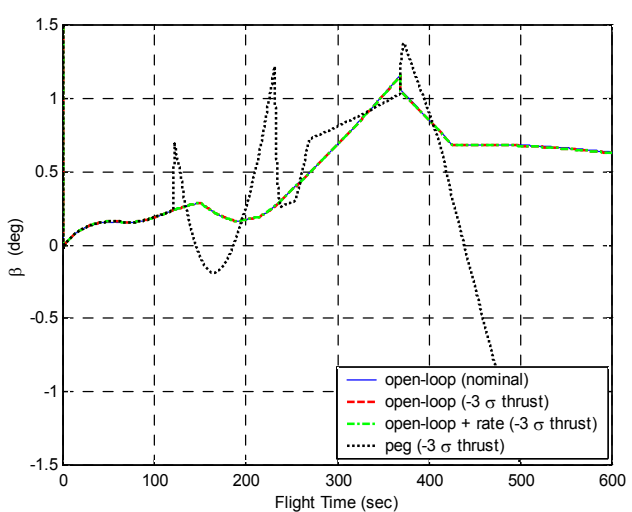

그림 14. 옆미끄럼각 ( $-3 \sigma$ 추력오차)

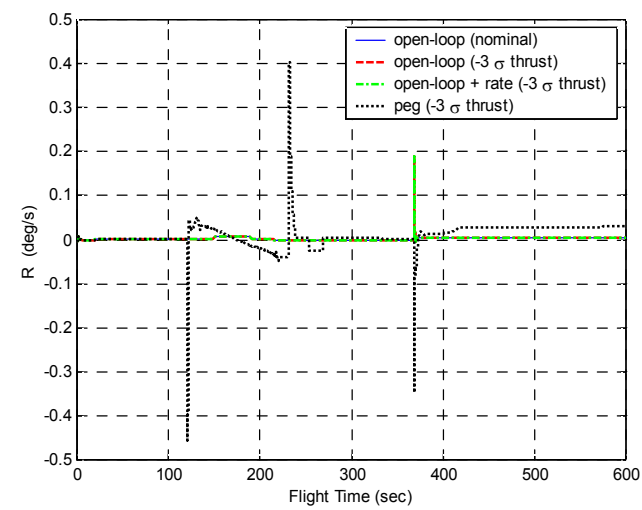

그림 15. 요 제어각 ( $-3 \sigma$ 추력오차)

나 여기서는 $t_{g o}$ 와 관계없이 일정하게 두었다. 그 림 13 부터 15는 추력변화가 있는 경우의 모의시 험 결과를 나타낸다. 추력변화에 의해서 (c)의 피 치각속도 적분값은 유도시작시점과 종료시점에서 nominal 값에 비해서 변화가 생기며, 요 제어각, 
옆미끄럼각, 요각속도도 nominal 값에 비해서 증 가함을 알 수 있다. 여기서는 생략했으나 다른 파라미터 변화에 대해서도 비슷한 결과를 보인 다.

\section{$\mathrm{IV}$. 결 론}

본 논문에서는 위성발사체의 폐루프 유도방식 중 하나인 $\mathrm{PEG}$ 에 대해서 연구하였다. 기존에 연 구된 결과를 바탕으로 계산 속도 향상을 위해서 반복 계산을 없앤 알고리듬 형태를 유도하고 추 력변화가 큰 엔진으로 구성된 위성발사체 모델에 적용해 보았다. 엔진 연소종료시점에서의 위치/ 속도 정밀도 분석을 위해서 6-자유도 모의시험을 수행하였다. 얻어진 결과는 정상 비행조건 및 파 라미터 변화와 바람 영향이 있는 비정상 비행조 건에서도 목표궤도 조건을 잘 만족시키며 개루프 명령 보다 더 우수한 성능을 보임을 확인할 수 있었다.

\section{참고문헌}

1) R. F. Jaggers, "An explicit solution to the exoatmospheric powered flight guidance and trajectory optimization problem for rocket propeller vehicles", AIAA 77-1051, 1977, pp. 566-578.

2) M. E. Hough, "Explicit guidance along an optimal space curve", J. Guidance, Vol. 12, No. 4, 1989, pp. 495-504.
3) S. K. Sinha and S. K. Shrivastava, "Optimal explicit guidance of multistage launch vehicle along three-dimensional trajectory", $J$. Guidance, Vol. 13, No. 3, 1990, pp. 394-403.

4) R. L. McHenry, T. J. Brand, A. D. Long, B. F. Cockrell, and J. R. Thibodeau III, "Space shuttle ascent guidance, navigation, and control", J. Astronautical Sciences, Vol. XXVII, No. 1, 1979, pp. 1-38.

5) S. K. Sinha and S. K. Shrivastava, "Explicit guidance of a rocket with non-uniform thrust", Acta Astronautica, Vol. 19, No. 6/7, 1989, pp. 555-560.

6) J. M. Hanson, M. Shrader, and C. A. Cruzen, "Ascent guidance comparison", The Journal of the Astronautical Sciences, Vol. 43, No. 3, 1995, pp. 307-327.

7) 노웅래, "위성발사체의 궤적최적화와 관성 유도알고리듬 설계에 관한 연구", 박사학위논문, 서울대학교, 2001.

8) 송은정, 안재명, 노웅래, 최형돈, "PEG (Powered Explicit Guidance) 알고리듬을 사용한 3단형 위성발사체 유도", 2004 춘계학술발표회, 한국항공우주학회.

9) H. J. Dhuyvetter and H. T. Lam, "Load relief for launch vehicles using an engine biasing technique", SAE Technical Paper Series 892305

10) R. M. Blackstock and Q. W. Klug, "AS-206A Launch vehicle operational flight trajectory dispersion analysis", TN-AP-66-156, 1966. 